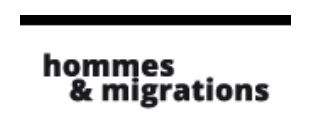

Hommes \& migrations

Revue française de référence sur les dynamiques

migratoires

$1327 \mid 2019$

Capitales européennes et diversité culturelle

\title{
Daniel Bougnoux et François L'Yvonnet (sous la direction), Cahiers de l'Herne : Jullien
}

Paris, L'Herne, 2018, 256 pages, $33 €$.

\section{Mustapha Harzoune}

\section{(2) OpenEdition}

Journals

Édition électronique

URL : https://journals.openedition.org/hommesmigrations/10536

DOI : 10.4000/hommesmigrations. 10536

ISSN : 2262-3353

Éditeur

Musée national de l'histoire de l'immigration

Édition imprimée

Date de publication : 1 octobre 2019

Pagination : 202

ISBN : 978-2-919040-47-6

ISSN : 1142-852X

Référence électronique

Mustapha Harzoune, « Daniel Bougnoux et François L'Yvonnet (sous la direction), Cahiers de l'Herne Jullien », Hommes \& migrations [En ligne], 1327 | 2019, mis en ligne le 01 octobre 2019, consulté le 08 janvier 2022. URL : http://journals.openedition.org/hommesmigrations/10536 ; DOI : https://doi.org/ 10.4000/hommesmigrations.10536 


\section{Cahiers de l'Herne : Jullien}

Daniel Bougnoux et François L'Yvonnet (sous la direction), Paris, L'Herne, 2018, 256 pages, $33 €$.

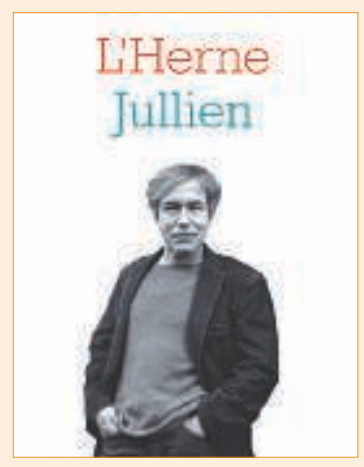

Quarante contributions sont ici rassemblées, consacrées à l'œuvre du philosophe et sinologue, portées notamment par Alain Badiou, Christian Bobin, André Chieng, Marcel Gauchet, Claude Hagège, Étienne Klein, Bruno Latour, Paul Ricœur ou Léon Vandermeersch, auxquelles s'ajoute un long entretien, en trois temps, avec

François Jullien lui-même.

Ce dernier, penseur de l'altérité, revisite la notion d'universel. Exit l'universalisme de domination, ethnocentrique et/ou mercantile, ou le «tous pareils» mollasson et relativiste, pour réfléchir à l'universel comme un processus en devenir. Un processus dont le mouvement ne serait pas porté par l'opposition d'«identités» fantasmées et d'hostiles «différences», mais par la notion d'«écart» et dans un rapport de «dia-logue» entre les cultures, ce «champ d'intelligence partagé où chacun peut commencer d'entendre l'autre». L'objet n'est plus de comparer ou classer, de séparer, d'idéaliser, mais de rendre possible, d'apprécier, de mettre en connivence les «ressources» de chacune. La «ressource»- notion "plus modeste et plus pratique» que celles de «vérité» ou de valeur - «a des vertus d'ouverture» écrit Hagège. Ouverture notamment sur le pensé et l'impensé des cultures.

L'universel devient un horizon, une «capacité universalisante» qui vise à construire, et reconstruire, du commun, non à le poser comme tel, une fois pour toutes, une abstraction à laquelle il faudrait se plier, mais à constater «qu'il est», et que les uns et les autres «appartiennent à» (Hagège). Pour Ratte, "l'entre est ainsi premier, et corrélativement universel. (...) Je n'existe que par l'ensemble de mes relations à mes semblables, et cependant je ne suis que par ma distinction d'envers eux tous, faute de laquelle ni eux ni moi n'aurions de réalité, puisque eux aussi obéissent à cette double détermination qui nous est commune». Philosophie de l'existence, «philosophie du vivre» (Ratte), la pensée de Jullien ouvre, via ses nombreux concepts («écart», «ressources», «entre», «tension», «transition», «transformation silencieuse», «connivence»...), sur les «possibles» de l'esprit, ce commun des ressources qui mérite d'être activé. Cet "effort», François Jullien l'a entrepris. C'est «du dehors», à partir de la Chine, à l'épreuve du dépaysement de la pensée, du décentrement, qu'il a interrogé l'héritage grec, permettant à la pensée occidentale de "sortir d'elle même et à penser ce qui n'est pas elle» (Gauchet).

Stimulante, érudite, pratique, la démarche de Jullien est essentielle en ces temps de "globalisation», portée aussi par les mouvements migratoires. "L'universel et l'altérité: voilà les questions que nous devons affronter dans un futur proche» (Gauchet). C'est dire si, dans le contexte migratoire, l'œuvre de Jullien referme des outils indispensables aux associations, éducateurs, acteurs de terrain et autres, en contact avec ces hommes, ces femmes et surtout ces enfants en quête de compréhension et de repères. "Je reviens encore et toujours à l'œuvre de François Julien, dont la lecture est indispensable à l'élaboration d'une éducation interculturelle» (Lucas).

Faut-il ajouter que, si Jullien n'a pas à barboter dans la mélasse des débats médiatiques et politiques (identité, nation, homogénéisation des individus, moraline et «compassion démonstrative», etc.), sa pensée permet de «résister à l'empâtement en cours» (Ratte), mais aussi de poser autrement les urgences collectives.

Ce Cahier de l'Herne offre un large tour d'horizon des possibles de cette pensée: philosophie bien sûr, mais aussi psychanalyse, droit, éducation, entreprise, art, écriture... C'est dire sa richesse et son influence. En France et au-delà: François Jullien est le philosophe français actuellement le plus traduit dans le monde.

M. H. 